\title{
Elaboração de mapa de danos de prédio histórico: um estudo de caso em fachadas com revestimento em pintura da Escola Politécnica da Universidade de Pernambuco
}

\section{Bruna Correia Teixeira 1,2 (Dorcid.org/0000-0001-5065-3681}

\author{
Angelo Just da Costa e Silva1 (Dorcid.org/0000-0002-0759-6439 \\ ${ }^{1}$ Escola Politécnica de Pernambuco, Universidade de Pernambuco, Recife, Brasil. \\ ${ }^{2}$ Graduação em Engenharia Civil, Escola Politécnica de Pernambuco, Pernambuco, Brasil.
}

E-mail do autor principal: Bruna Correia Teixeira bruunateixeira@gmail.com

\section{RESUMO}

A história de uma sociedade, bem como seus costumes e tradições, é transmitida através do tempo por meio de seu patrimônio cultural, independente da forma sob a qual ele se apresenta. Para tanto, é necessário que esses bens - móveis e imóveis - sejam preservados. Este trabalho se concentrou em diagnosticar o estado de conservação do patrimônio arquitetônico, aqui representado pelo Bloco A da Escola Politécnica da Universidade de Pernambuco, situado em Recife - PE. E, então, elaborar o mapa de danos do edifício, no qual constam as manifestações patológicas que o acometeram ao longo de suaexistência. Através da inspeção visual de três fachadas revestidas com pintura, foram identificados problemas como manchas, estufamento da pintura, fissuras e desagregação do revestimento, muitos dos quais tiveram como agente causador a umidade. 0 estudo das causas e efeitos dessas manifestações patológicas são imprescindíveis na concepção de estratégias de intervenção para a preservação do patrimônio edificado.

PALAVRAS-CHAVE: Patrimônio arquitetônico; Mapa de danos; Manifestações patológicas

\section{ABSTRACT}

The history of a society, as well as its customs and traditions, is transmitted through time through its cultural patrimony, regardless of the form under which it presents itself. Therefore, it is necessary that this patrimony are preserved. This work focused on the diagnosis of the conservation status of the architectural patrimony, represented here by Building A of the Polytechnic School of the University of Pernambuco, situated in Recife - PE. The Damage Map of the building was elaborated, which includes the pathological manifestations that affected it throughout its existence. Through visual inspection of three facades coated with paint, problems were identified such as stains, cracking and disintegration of the coating, many of which had moisture as the causative agent. The study of the causes and effects of these pathological manifestations are essential in the conception of intervention strategies for the preservation of the built heritage.

KEY-WORDS: Architectural patrimony; Damage map; Pathological manifestations. 


\section{INTRODUÇÃO}

A principal função do patrimônio cultural produzido por uma civilização é transmitir sua história através do tempo. Segundo Costa, p. $19[1]$, define-se patrimônio cultural como "o conjunto de elementos culturais e naturais, materiais e imateriais, herdados de seus antepassados ou criados no presente, em que uma comunidade reconhece e se identifica e que deve ser transferida a gerações futuras".

A preocupação para com a transmissão desses bens ao futuro surgiu no século $X V$, com o intuito de resguardar riquezas e edificações pertencentes à Igreja [2]. No final do XVIII, decorrente de modificações causadas pela industrialização e da precariedade na qual se encontrava o patrimônio histórico da França, nasceu o cuidado em se preservar, em particular o patrimônio arquitetônico, objeto de estudo deste trabalho [1].

Sob esta nova ótica de encarar a preservação patrimonial tiveram início movimentos de salvaguarda e restauração arquitetônica, responsáveis por traçar o que viria a ser o escopo das políticas de proteção atuais. No Brasil, o Decreto-Lei 25 de 30 de novembro de 1937foi o pioneiro na regulamentação da preservação de monumentos históricos e artísticos do país. Em Recife, os sítios históricos passaram a ser protegidos na década de 70 pela Lei Municipal $n^{\circ}$ 13.957 de 26 de dezembro de 1979 [3, 4].

Consolidada, nacional e internacionalmente, a relevância de se preservar o patrimônio histórico edificado, metodologias e ciências foram criadas de modo a tornar possível a avaliação do estado de degradação do edifício, sem que haja mais comprometimento da sua estrutura, e sua posterior manutenção ou restauração.

A deterioração de uma edificação é observada a partir das manifestações patológicas que ela apresenta fisicamente, de maneira visível ou não. Essas manifestações são estudadas pela Patologia das Edificações e podem ser verificadas através de análise visual e de ensaios realizados a partir dos chamados métodos destrutivos e não destrutivos.

\section{PRESERVAÇÃO PATRIMONIAL}

O patrimônio histórico cultural é uma ferramenta na construção de identidade e perpetuação de memórias e tradições de um povo. É, portanto, dispositivo essencial na criação de subjetividade coletiva: os grupos sociais 2 reconhecem nele a sua história, provocando-Ihes, assim, uma ideia de pertencimento àquele lugar.

Entende-se como patrimônio cultural tudo aquilo, seja objeto, edificação ou ambiente, ao qual a sociedade atribua valor especial (estético ou artístico, por exemplo) e cuja transmissão às gerações futuras seja essencial [5].

Apesar de em 1462 o clero, na figura do Papa Pio II, apresentar preocupação com a preservação de edificações e outras riquezas artísticas pertencentes à Igreja, foi durante o século XVIII, sob influência do Iluminismo, que a ideia de historicismo começou a evoluir, ainda que devagar. Esses fatores associados ao estado de degradação do patrimônio francês na época e às modificações oriundas do processo de industrialização na GrãBretanha fizeram com que, no final desse século e início do século XIX, a relação com as representações artísticas do passado mudasse. A partir de então, torna-se relevante o resguardo dos monumentos arquitetônicose estes passam a ser objetos de interesse de inúmeros movimentos de preservação e restauração que surgem como consequência da mudança de pensamento acerca da herança cultural deixada por um povo: agora, não só as obras da Antiguidade Clássica são significativas e carecem de preservação $[\mathbf{1}, \mathbf{2}]$.

No âmbito nacional, também no século XVIII, a preocupação do então Vice-Rei do Estado do Brasil (1735 a 1749) sobre os edifícios deixados em Pernambuco pelos holandeses foi a primeira atividade que visou a salvaguarda de prédios históricos da qual se tem registro [1].

Na década de 1920 alguns projetos de lei foram desenvolvidos a fim de criar um instrumento legal voltado à preservação patrimonial, mas não vogaram. Apenas em 30 de novembro de 1937 o Decreto-Lei $n^{\circ} 25$ foi promulgado como a primeira lei de preservação brasileira, sendo a mais antiga lei da América Latina e tornando, assim, o Brasil um dos principais atores na preservação latinoamericana [4].

No mesmo ano, a Lei $n^{\circ} 378$, de 13 de janeiro, instaura o Serviço do Patrimônio Histórico e Artístico Nacional - SPHAN, a primeira instituição nacional de preservação do patrimônio. Em 1946, o SPHAN passou à classe de Diretoria, tornando-se DPHAN. Por fim, a evolução da então Diretoria à Instituto, em 1970, deu origem ao que se conhece hoje como IPHAN [1].

A promulgação da Constituição Federal de 1988 acabou por ratificar a proteção do patrimônio cultural que, segundo seu artigo 216 , "são os bens 
de natureza material e imaterial, tomados individualmente ou em conjunto, portadores de referência à identidade, à ação, à memória dos diferentes grupos formadores da sociedade brasileira" [6].

De acordo com a Constituição [6], fazem parte do patrimônio cultural nacional:

- as formas de expressão;

- os modos de criar, fazer e viver;

- as criações científicas, artísticas e tecnológicas;

- as obras, objetos, documentos, edificações e demais espaços destinados às manifestações artístico-culturais;

- os conjuntos urbanos e sítios de valor histórico, paisagístico, arqueológico, paleontológico, ecológico e científico.

Em Recife, a década de 1970 foi marcada pela crescente atenção à questão patrimonial. Além da promulgação da Lei Municipal n 13.957 em 26 de dezembro de 1979, responsável por reger a proteção dos sítios históricos, foi elaborado o Plano de Preservação dos Sítios Históricos da Região Metropolitana e criado o Departamento de Planejamento dos Sítios Históricos - DPSH, com o intuito de levantar, fiscalizar as áreas de preservação e elaborar projetos de intervenção [3].

\section{PATOLOGIA DAS ESTRUTURAS}

A não preservação do patrimônio edificado implica a degradação do imóvel, que pode ser identificada pela manifestação física de defeitos por toda a estrutura. A ciência a qual cabe estudar os mecanismos de deterioração das edificações é a Patologia das Estruturas.

Souza e Ripper [7] conceituam esta ciência como o ramo da Engenharia Civil responsável pelo estudo das origens, formas de manifestação, consequências e mecanismos de ocorrência dos defeitos e dos sistemas de degradação das estruturas.

Ainda segundo os autores, as manifestações patológicas incidentes nas estruturas podem ser classificadas como simples ou complexas. As simples são os problemas cujo diagnóstico e profilaxia são evidentes. Por sua vez, osproblemas considerados complexos são aqueles que requerem uma análise individual e meticulosa, exigindo conhecimentos profundos acerca da Patologia.
Quanto aos agentes causadores dessa degradação, Ribeiro [8] cita três: o próprio homem, através de atos de vandalismos; o que a autora chama de causas imprevistas, como guerras ou fenômenos naturais; e o meio ambiente no qual a edificação está inserida. A autora ainda classifica as causas das manifestações patológicas como de ordem intrínseca, aquelas oriundas dos materiais empregados na construção, ou de ordem extrínseca, provenientes de fatores externos.

As causas intrínsecas podem ser exemplificadas como as falhas humanas durante a execução da obra e/ou durante o uso da edificação, além das causas naturais. As causas extrínsecas envolvem as falhas de projeto e ações biológicas, químicas, físicas e mecânicas [7].

Tavares [4] apresenta os agentes que atuam sobre o edifício e suas partes constituintes conforme classificação da ISO 6241/1983:

- agentes mecânicos: gravidade, esforços e deformações impostas ou restringidas, energia cinética, vibrações e ruídos;

- agentes eletromagnéticos: radiação, eletricidade e magnetismo;

- agentes térmicos;

- agentes químicos: água e solventes, oxidantes, redutores, ácidos, bases, sais, neutros;

- agentes biológicos: micro-organismos vegetais e animais.

No tocante aos problemas patológicos comumente observados nas fachadas das construções localizadas em Recife, Matias e Póvoas [9] concluíram que o principal é o descolamento do revestimento cerâmico, presente em $37 \%$ das edificações estudadas, seguido do bolor, escurecimento de rejunte, mancha de água, destacamento de tinta e eflorescência. A Figura 1 demonstra os resultados obtidos.
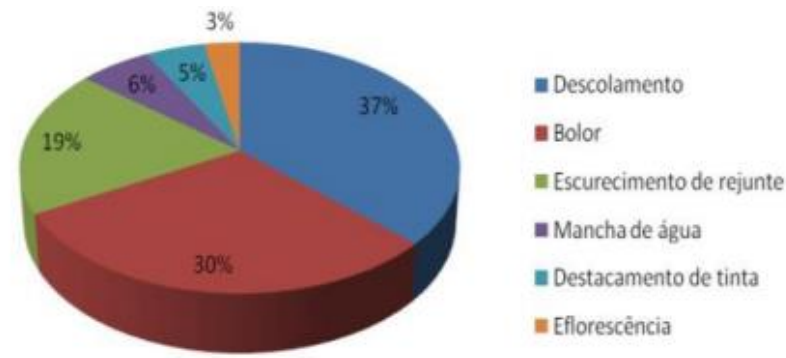

Figura 1:Principais manifestações patológicas existentes nas fachadas de edificações da cidade do Recife

Fonte: [9]. 
É importante salientar que a presença de manifestações patológicas em prédios antigos costuma ser mais crítica em comparação à sua ocorrência em edificações novas, em virtude da idade avançada da estrutura e, consequentemente, da sua maior exposição a um ambiente agressivo.Isto posto, o diagnóstico também tende a ser mais complexo e criterioso.

\section{METODOLOGIA}

O IPHAN [10] designa três etapas para a fundamentação de um projeto de preservação do patrimônio cultural:

- identificação e conhecimento do bem;

- diagnóstico; e

- proposta de intervenção.

Visto que o objetivo deste trabalho é a elaboração de um mapa de danos para um edifício histórico, atentou-se apenas para as duas primeiras etapas.

A identificação e conhecimento do bem significa conhecer e analisar a edificação sob um ponto de vista histórico, estético, formal e técnico. Além disso, busca compreender a mudança de significação do patrimônio ao longo do tempo [10].

Nesta primeira etapa, foram privilegiadas apenas algumas das suas atividades componentes previstas pelo Manual de Elaboração de Projetos de Preservação do Patrimônio Cultural, como: pesquisa histórica, análise tipológica da arquitetura do imóvel, os materiais empregados e o contexto no qual está inserida.

$\mathrm{Na}$ fase de diagnóstico foi elaborado o mapa de danos, que consiste na documentação ilustrativa das anomalias (materiais, funcionais ou estéticas) na qual serão embasados os trabalhos de intervenção conservativa ou de restauração. Em outras palavras, é a representação gráfica dos danos presentes na edificação, relacionando-os aos seus agentes e causas $[10,11]$.

A análise do estado de conservação do patrimônio edificado foi realizada a partir de inspeção visual, em três fachadas do mesmo e restringiu-se à avaliação do estado de conservação dos materiais e à identificação dos agentes degradadores.

\section{IDENTIFICAÇÃO DO BEM}

O estudo de caso foi realizado no Bloco $A$ da Escola Politécnica da Universidade de Pernambuco, sediada, desde 1937, no número 455 da Rua Benfica, no bairro da Madalena, em Recife - PE.

Fundada em 6 de janeiro de 1912 e inaugurada em $1^{\circ}$ de janeiro do ano seguinte, a Escola Politécnica foi idealizada em 1911 por um grupo de educadores em resposta à promulgação da Lei Rivadávia Corrêa, que propiciava a desoficialização do ensino no país. Assim, o Estado deixou de ter a titularidade do monopólio da validade oficial dos diplomas e certificados $[12,13]$.

Antiga moradia de Fausto Pinheiro, o atual Bloco A, que hoje abriga salas de aula e o auditório da Escola, foi descrito à época da mudança da Escola para a nova sede:

\section{O casarão de construção sólida, com dois pavimentos, todo em alvenaria, acabamento de primeira, com a frontaria azulejada em róseo, as laterais guarnecidas por alpendres e portas pesadas, dava aparência de uma mansão faustosa [...]. [13, p. 32].}

No que se refere às fachadas, algumas modificações foram feitas ao longo dos anos. A Figura 2 ilustra a fachada original, datada de 1937, enquanto a Figura 3 mostra a fachada atualmente.

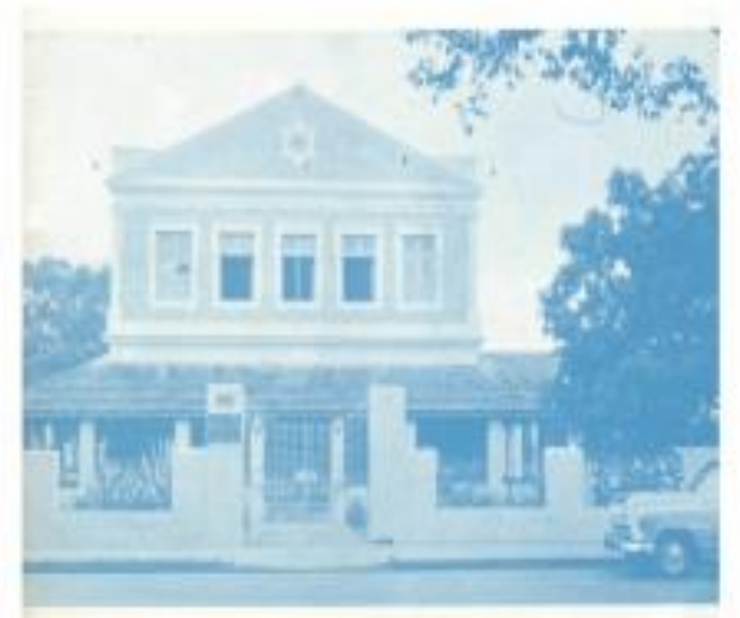

Figura 2: Bloco A - fachada original. Fonte: [14]. 


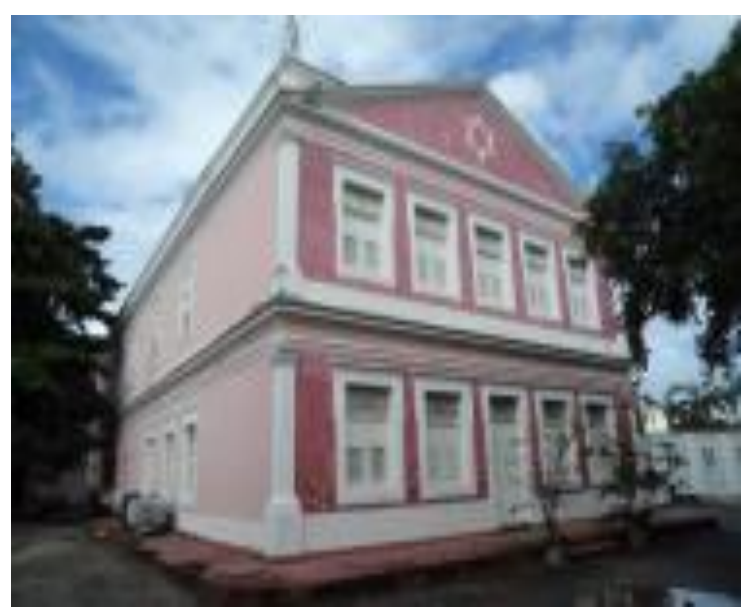

Figura 3: Bloco A - fachada atual Fonte: [14].

O casarão é um típico exemplo da arquitetura neoclássica que vigorou nas residências da capital pernambucana durante o século XIX. Deste modo, é fácil identificar na sua fachada os elementoschave desse estilo, como o frontão triangular e as colunas gregas, cujos capitéis simples remetem à ordem dórica.

\section{DIAGNÓSTICO}

Esta etapa restringiu-se ao estudo das manifestações patológicas das três fachadas não azulejadas do Bloco $A$, que possuem revestimento em pintura na cor rosa e detalhes arquitetônicos pintados de branco.

O Quadro 1 apresenta o mapeamento dos danos observados e a Figura 4 mostra o Mapa de Danos, identificando os locais onde os defeitos se manifestaram ao longo das fachadas 1,2 e 3, que foram representadas planificadas. 


\subsection{Mapa de danos}

Quadro 1: Mapeamento de danos observados nas fachadas com revestimento em pintura do Bloco A (continua).

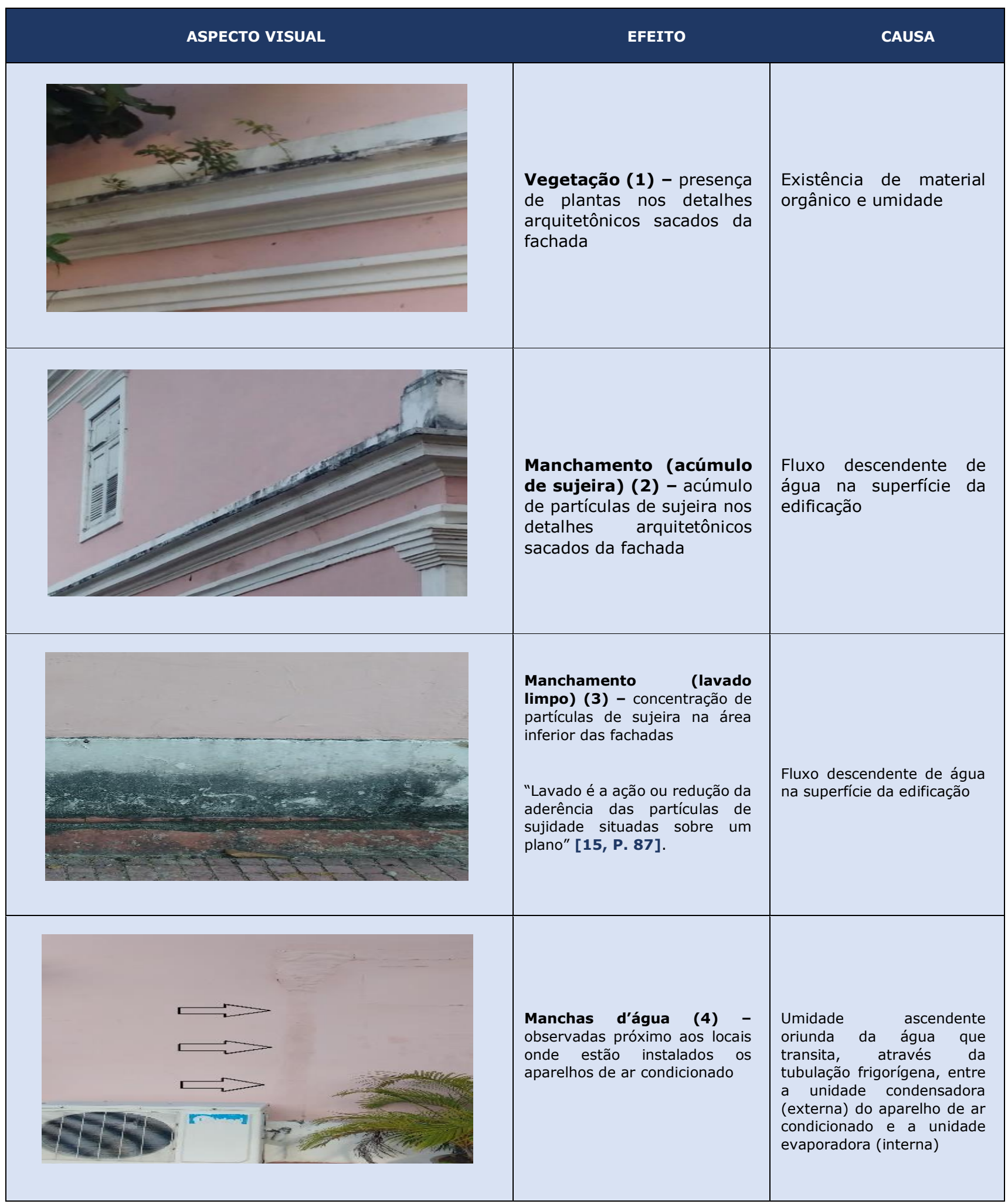


Quadro 2: Mapeamento de danos observados nas fachadas com revestimento em pintura do Bloco A (continuação).

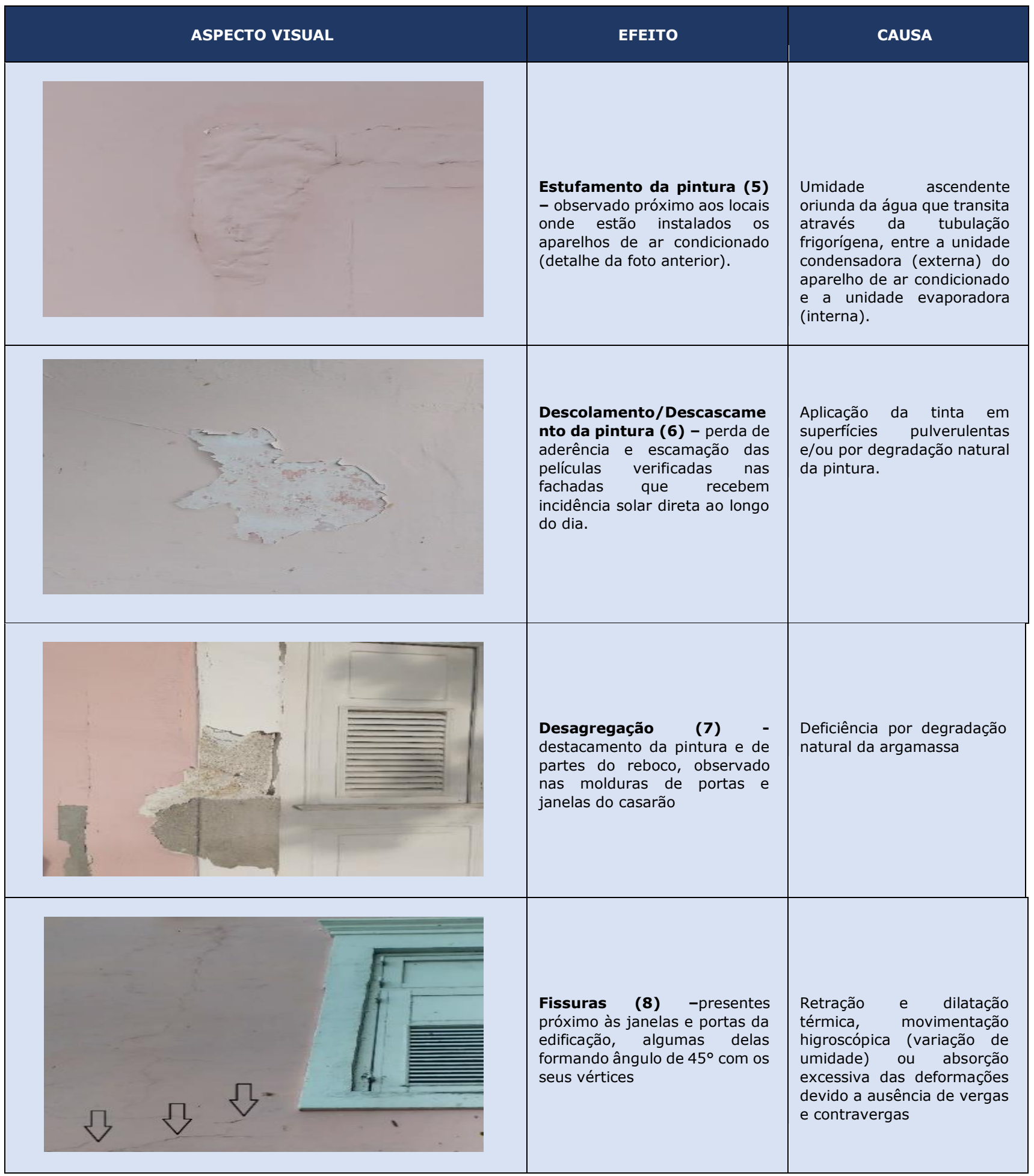


Quadro 3: Mapeamento de danos observados nas fachadas com revestimento em pintura do Bloco A (continuação).

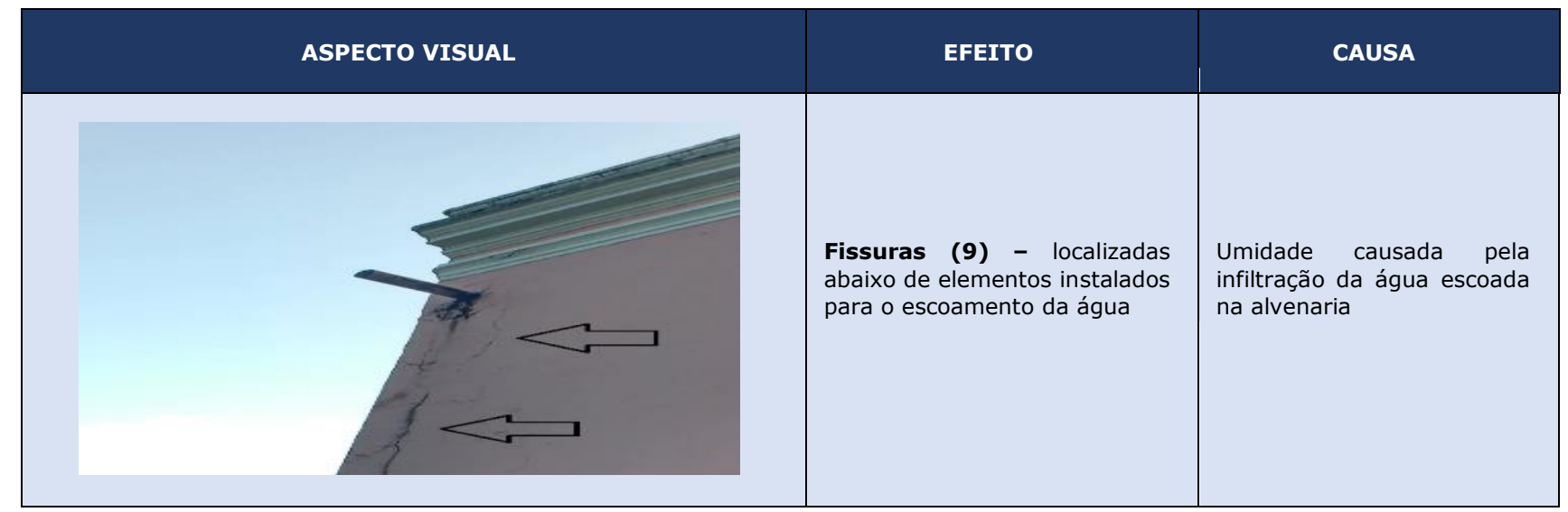

Fonte: [Os autores].

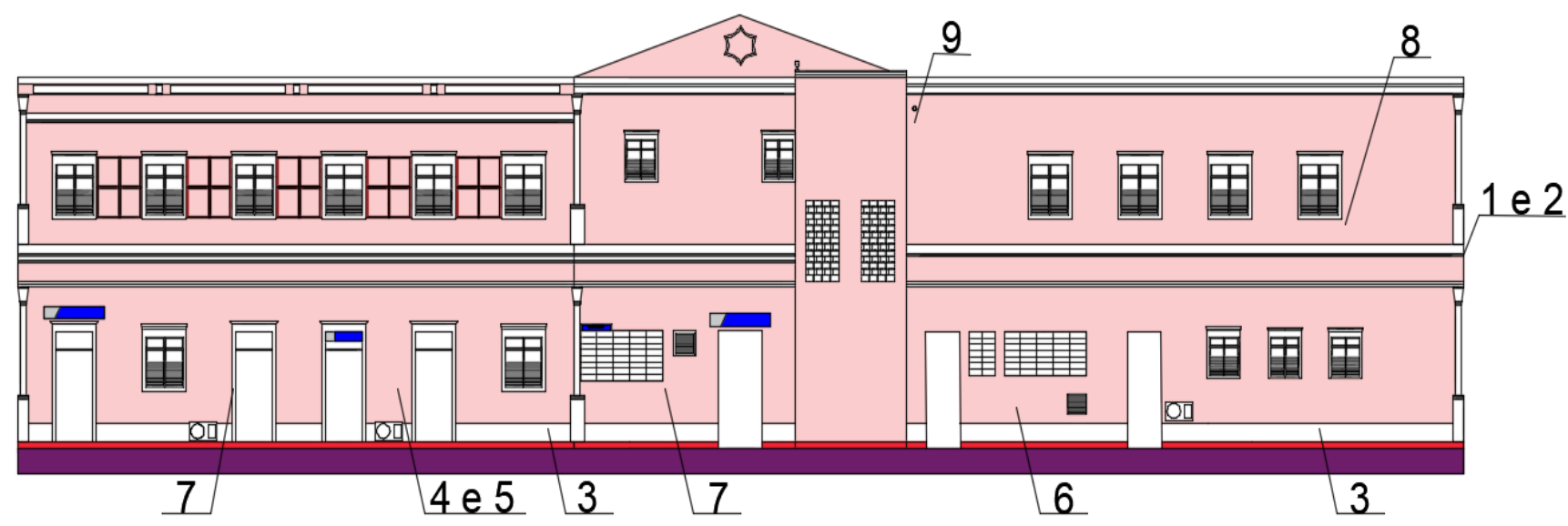

Figura 4: Mapa de danos das fachadas 1, 2 e 3 (da esquerda para a direita). Fonte: [Os autores].

\section{CONCLUSÕES}

Assim comoas demais formas sob as quais o patrimônio cultural se apresenta, as edificações que o compõempossuem valor ímpar pelos aspectos históricos, sociais, econômicos e ambientais que representam.

Devido à sua relevância para a transmissão da história dos povos às gerações futuras, é de suma importância que o patrimônio edificado seja preservado. Deste modo, o primeiro passo para que seja executada uma obra de intervenção é diagnosticar o estado de conservação do edifício.

O mapa de danos das fachadas não azulejadas do Bloco A da Escola Politécnica da Universidade de Pernambuco forneceu um panorama das manifestações patológicas presentes no edifício, de modo que, sabendo suas causas e efeitos, pode-se elaborar uma estratégia de intervenção específica para que o casarão possa ser restaurado sem que sofra mais danos.

Os principais agentes de degradação observados foram agentes mecânicos, químicos e biológicos. A maioria dos problemas patológicos encontrados se deu em decorrência da presença de umidade na edificação, causada por fatores tais quais a ausência de impermeabilização da estrutura aliada ao clima quente e úmido da cidade.

Cabe ressaltar, entretanto, que a identificação das manifestações patológicas apenas quando elas estão visíveis limita as possibilidades de correção e de redução do problema. Assim posto, a conservação do patrimônio arquitetônico deve ser feita de forma constante. 


\section{REFERÊNCIAS}

[1] COSTA, D. R. M. Aspectos críticos em obras de restauração arquitetônica no estado: a experiência do arquiteto Edegar Bittencourt da Luz. Trabalho de Conclusão de Curso (Mestrado Profissionalizante em Engenharia) - Escola de Engenharia, Universidade Federal do Rio Grande do Sul, Porto Alegre, 2005.

[2] KÜHL, B. M. Preservação do ferro e arquitetura ferroviária em São Paulo: reflexões sobre sua preservação. São Paulo: Ateliê Editorial; Fapesp; Secretaria da Cultura, 1998.

[3] MELO, J. M. Mais além da Rua do Bom Jesus: a revitalização do Bairro do Recife, a população e outros usos do local. Dissertação (Mestrado) - Programa de Pós-Graduação em Antropologia, Universidade Federal de Pernambuco, Recife, 2003.

[4] TAVARES, F. M. Metodologia de diagnóstico para restauração de edifícios dos séculos XVIII e XIX nas primeiras zonas de mineração em Minas Gerais. Dissertação (Mestrado em Ambiente Construído) - Faculdade de Engenharia, Universidade de Juiz de Fora. Juiz de Fora, 2011.

[5] BRAGA, M. História e evolução conceitual do restauro arquitetônico. In: Márcia Braga (org.)

Conservação e Restauro: arquitetura brasileira. Rio de Janeiro: Ed. Rio, 2003.

[6] BRASIL. Constituição da República Federativa do Brasil. Brasília: Senado Federal: Secretaria de Editoração e Publicações:

Coordenações de Edições Técnicas, 1988. Disponível em:

https://www.senado.gov.br/atividade/const/con1 988/CON1988_05.10.1988/art_216_.asp. Acesso em: 28 jul. 2017 .

[7] SOUZA, V. C. M. de; RIPPER, T. Patologia, recuperação e reforço de estruturas de concreto. São Paulo: Pini, 1998.

[8] RIBEIRO, R. T. M. Patologias nas construções históricas. In: BRAGA, Márcia (org.)

Conservação e Restauro: arquitetura brasileira. Rio de Janeiro: Ed. Rio, 2003.

[9] MATIAS, G. A.; PÓVOAS, Y. V. Estudo de métodos construtivos e materiais aplicados no revestimento cerâmico em fachadas de edificações. Trabalho de Conclusão de Curso (Graduação em Engenharia Civil) - Universidade de Pernambuco, Recife, 2009.

9
[10] BRASIL. Ministério da Cultura. Instituto do Programa Monumenta. Manual de elaboração de projetos de preservação do patrimônio cultural. Brasília: Ministério da Cultura, Instituto do Programa Monumenta, 2005.

[11] COSTA, L. G.; BAISCH, L. F. CRONIDAS: Proposta de padronização de representação em mapas de danos. In: ZANCHETTI, Silvio; AZEVEDO, Gabriela; MOURA, Carolina (org.) A conservação do patrimônio no Brasil: Teoria e prática. Olinda: Centro de Estudos da Conservação Integrada, 2015.

[12] CURY, C. R. J. A desoficialização do ensino no Brasil: a reforma Rivadávia. Educação \& Socociedade, Campinas, v. 30, n. 108, p. 717-738, out. 2009. Disponível em: http://www.scielo.br/pdf/es/v30n108/a0530108.p df. Acesso em: 9 nov. 2019.

[13] SANTOS, M. H. R. dos. Escola Polytechnica de Pernambuco: 1911 a 1991. Recife: Companhia Editora de Pernambuco, 2012.

[14] SANTOS, C. L. L. dos; SILVA, A. J. da C. Conservação de edifício histórico do século XIX análise de patologias na fachada do Bloco $\mathrm{A}$ da Escola Politécnica da Universidade de Pernambuco. In: CONFERËNCIA NACIONAL DE PATOLOGIA E RECUPERAÇÃO DE ESTRUTURA, $1 .$, 2017, Recife. Anais eletrônicos... Recife: Escola Politécnica de Pernambuco, 2017. Disponível em: http://revistas.poli.br/index.php/CONPAR/article/ view/599. Acesso em: 16 set. 2017.

[15] VIEIRA, A. de A. Influência dos detalhes arquitetônicos no estado de conservação das fachadas de edificações do patrimônio cultural do centro histórico de Porto Alegre: estudo de caso. Trabalho de Conclusão de Curso (Mestrado Profissionalizante em Engenharia) Escola de Engenharia, Universidade Federal do Rio Grande do Sul, Porto Alegre, 2005. 